\title{
Polymorphisms of CYP1A1* 4 and GST as Susceptibility and Prognostic Genes for Acute Myeloid Leukemia
}

\author{
Heba $M^{\mathrm{a}}$, Ahmed $\mathrm{A}^{\mathrm{b}}$ and Sheriff $\mathrm{E}^{\mathrm{c}}$ \\ Departments of a Clinical Pathology, ${ }^{b}$ Microbiology and Internal Medicine, Tanta University and Mansoura \\ University
}

\begin{abstract}
Introduction: Associations between polymorphisms for genes encoding enzymes involved in biotransformation of xenobiotics and susceptibility to several cancers have been shown in several studies. The aim of the study is to investigate the influence of cytochromes P450 (CYP1A1*4) and Glutathione S-transferases (GSTS) (T1 and M1) gene polymorphisms in susceptibility to acute myeloid leukemia (AML) as well as their prognostic role for the treatment outcome in AML patients. Material and Methods: This study included 65 individuals classified as healthy controls and newly diagnosed AML patients. BMA and immunophenotyping assay by flowcytometry were done at D1 and D14 following treatment induction to assess the complete remission or non response to treatment in AML patients. The CYP1A1*4 and of GSTT1and GSTM1 genotypes were examined using polymerase chain reaction (PCR)-based methods. Results: A higher prevalence of the CYP1A1*4 (CA and $A A$ ) genotype was found in $A M L$ patients than in controls (37\% vs $23.3 \%, O R=3.25,95 \% \mathrm{Cl}$. 1.01-10.46, $p=0.05$ ). GSTT1 null genotype were also more frequent in AML patients than in controls (58\% vs $26.7 \%$, OR $=3.79$, 95\% Cl 1.11-12.87, $p=0.03$ ). The combination of GSTT1 null genotype and CYP1A1 *4 (AA) genotype further increased the risk of $A M L(O R=12.66,95 \% \mathrm{Cl} 1.19-128.6, p=0.03$. Conclusion: GSTT1 null genotype appears to modulate individual's susceptibility of AML patients to treatment response, especially when combined with CYP1A1*4 (AA) genotype suggesting gene-gene interactions.
\end{abstract}

KEYWORDS: CYP1A1*4, Glutathione S-transferase, Acute myeloid leukemia

\section{INTRODUCTION}

Acute myeloid leukemia (AML) is the most common acute leukemia in adults. ${ }^{1}$ On the whole, acute leukemia is more common in males of all age groups a fact that remains unexplained. ${ }^{2}$ Although the clinical and biological aspects of leukemia are well documented, little is known about the factors that condition an individual's susceptibility to de novo leukemia. Normal polymorphic variations in several genes, together with dietary effects, environmental exposure to carcinogens, and individual immune system characteristics are likely to be factors that predispose individuals to develop acute leukemia. ${ }^{3}$

DNA damage in the hematopoietic precursor cell is the essential prerequisite for the development of acute myeloid leukemia (AML). Such damage may result from the interaction of reactive species generated by environmental or endogenous metabolites. ${ }^{4}$

Corresponding author;

Heba Mourad

Clinical Pathology Department, Tanta University

e-mail: hebamourad@hotmail.com
The carcinogenic effect of xenobiotics is influenced by a series of genes codifying enzymes involved in oxidation/activation (phase I) and conjugation/detoxification (phase II) of these compounds. Polymorphisms of these genes, resulting in functional allelic variants of the corresponding enzymes, have been shown to influence the risk of developing solid tumors and hematologic malignancies and can also modify individual response to cytotoxic treatment. ${ }^{5}$

CYP1A1 belongs to the cytochrome P450 family and is a phase I enzyme involved in the bioactivation of several chemical carcinogens, including polycyclic aromatic hydrocarbons (PAH). ${ }^{6}$ Oxidation of PAH produces an epoxide, a very reactive electrophilic group which can interact with DNA resulting in the formation of DNA adducts. Usually these epoxides are rapidly hydrolyzed into hydroxyl groups, which are then coupled to glucuronic acid, glutathione or other groups, producing water-soluble compounds that can then be excreted (phase II). ${ }^{6,7}$ Polymorphisms in the CYP1A1 gene have been described. The T6235C mutation is located 1194 bp downstream of exon 7 and when present alone corresponds to the CYP1A*2A allele. ${ }^{8}$ The $A 4889 \mathrm{G}$ mutation results in replacement of lle by Val at residue 462 in exon 7 , corresponding to the heme-binding region of CYP1A1. This mutation is in linkage disequilibrium with the T6235C mutation 
(CYP1A1*2B allele). ${ }^{9}$ The C4887A mutation results in the replacement of Thr by Asn in codon 461, near the site of the A4889G mutation (CYP1A1*4 allele). ${ }^{10}$

Phase II enzymes catalyze the conjugation of glutathione or glucuronide with reactive electrophiles and thus detoxify procarcinogens and carcinogens. ${ }^{11}$ Glutathione S-transferases (GSTs) belong to the group of phase II enzymes. These are widely expressed in mammalian tissues and have broad substrate specificity. GSTs are polymorphic genes and involved in the metabolism of a wide range of xenobiotics, including environmental carcinogens, chemotherapeutic agents and reactive species. The frequencies of GSTs polymorphic alleles especially GSTT1 and GSTM1 have been reported in various cancers. ${ }^{12}$

Homozygous deletions of GSTM1and GSTT1 are present in a large proportion of individuals as a genetic polymorphism. This causes absence of the specific enzymatic activity. There is increased risk for some solid tumors when there is a combination of the GST1 homozygous deletions with polymorphisms of phase I reaction enzymes together with prolonged exposure to external carcinogens, such as tobacco. ${ }^{13}$

Immunophenotyping improves both accuracy and reproducibility of acute leukemia classification and is considered particularly useful for identifying poorly differentiated subtypes of acute leukemia, acute myeloid leukemia (AML) with lymphoid marker expression and acute lymphatic leukemia (ALL) with myeloid marker expression. ${ }^{14}$ Murat et al, 2001 suggested that some patients with AML had both myeloid and lymphoid antigens. CD7, a pan T cell antigen, is one of the known lymphoid antigens expressed on AML cells. ${ }^{15}$ CD7 has been detected on the leukemic cells in a minority of AML cases. CD7-positive AML originates from early hematopoietic precursors and indicates biologic aggression in a significant proportion of patient. ${ }^{16,17}$ Expression of CD7 in association with "immature antigens" has prompted studies to evaluate its effect on clinical course and treatment response. The effect on prognosis is controversial, with reports of adverse prognosis. $C D$ 7+ AML patients have a significantly lower response rate and poorer prognosis than CD 7- AML patients. ${ }^{18}$

Although several parameters are useful for risk stratification of patients with AML, there are no firm criteria for predicting response to induction treatment of individual patients. ${ }^{19}$ Advances in chemotherapy and supportive care have significantly improved the prognosis of patients with $A M L$, but a fair number of them fail to respond to induction therapy and many patients who achieve complete remission (CR) relapse within two years. Poor outcome of adult AML has been associated with advanced age, increased CD34 cell surface marker expression, increased LDH level and specific cytogenetic abnormalities. ${ }^{20}$

An earlier bone marrow (BM) evaluation has been shown to predict those patients that will or will not achieve CR. ${ }^{21}$ BM aspiration on the day14th after chemotherapy induction may help to distinguish between patients likely to achieve CR or to fail to benefit from standard chemotherapy. ${ }^{22}$ Therefore, the aim of the present study is to evaluate the association between CYP1A1 and GST genotypes and the risk of predisposition to acute myeloid leukemia, also to explore the possible interactions between CYP1A1 and GST genotypes with other prognostic markers on the response of patients to treatment.

\section{MATERIALS AND METHODS}

This study included 50 newly diagnosed patients with do novo acute myeloid leukemia selected from the Hematology Oncology Unit of Medicine Department of Tanta University Hospital. 15 healthy individuals with matched age and sex were included in the study as a control group. The diagnosis of AML was based on clinical picture, morphological and cytochemical studies as well as immunophenotypic analysis, including CD7. ${ }^{23}$ Patients were treated with combination of Ara-C $1 \mathrm{gm} / \mathrm{m} 2 / 12 \mathrm{~h}$ (7days) or mitoxanthrone $12 \mathrm{mg}$ $/ \mathrm{m} 2$ (day $3,4,5$ ). Bone marrow was done on the 14 th day after treatment induction. Patients were judged to have achieved complete remission (CR) when bone marrow aspirate showed trilineage regeneration with blast < $5 \%$ by morphologic and cytochemical analysis in the presence of a normal blood count that persisted for at least 1 month. All other patients were considered to be non-responsive.

\section{The studied individuals were classified as follows;}

Group I: 15 healthy individuals served as a control group. Their age ranged from 22 to 75 years with a mean of 47years, they were 6 females and 9 males. These individuals had no medical history of any type of cancer and were not related to the patients.

Group II: 50 newly diagnosed AML patients. They were 16 females and 34 males. Their age ranged from 21-76 years with mean age of 49 years.

All the studied groups were subjected to the following;

1. Proper history taking and through clinical examination

2. Routine laboratory investigations including, complete blood count (CBC), erythrocyte sedimentation rate (ESR) and serum level of lactic dehydrogenase enzyme (LDH).

3. Bone marrow aspiration and flowcytometry assay were performed to establish diagnosis of AML and to assess the presence of CD7 marker (using FACs caliber flow cytometry, BD, Bectom Dickinson).

4. Genetic determination of the CYP1A1*4 and GST polymorphism using PCR based method

\section{Samples and DNA extraction}

Venous blood samples were collected from control subjects, or from patients at diagnosis into vacuum 
tubes containing EDTA.K3. The DNA was extracted directly from $500 \mu \mathrm{L}$ aliquots of whole blood using large volume MagNA Pure LC DNA Isolation kits (Roche, Mannheim, Germany).

\section{Determination of CYP1A1 *4 (C 4887A) polymor- phism}

CYP1A1 C4887A gene was determined using primers (5-CTGTCTCCCTCTGGTTACAGGAAGC-3 and 5-TTCCACCCGTTGCAGCAGGATAGCC-3).

PCR reactions were performed in $25 \mu \mathrm{l}$ containing 50 ng of genomic DNA, 12.5 pmol each primer, $200 \mu \mathrm{M}$ of each dNTPs, $2.5 \mathrm{mM} \mathrm{MgCl} 2$ and 0.5 units Hotstart Taq DNA Polymerase. After denaturation for 10 minutes at $95^{\circ} \mathrm{C}$, each PCR was performed for 35 cycles of 1 minute at $95^{\circ} \mathrm{C}, 1$ minute at $59^{\circ} \mathrm{C}$ and 1.5 minutes at $72^{\circ} \mathrm{C}$. The final elongation step was 10 minutes. and Bsa I was used to digest the 204-bp product: CYP1A1 C4887A CC (wildtype) produced two bands, a 138-bp and 66-bp, CYP1A1 C4887A AA (homozygote mutation) produced one band of 204-bp, while CYP1A1 C4887A CA (heterozygote) samples exhibited a digestion pattern of all three bands (204-bp, 138-bp and 66-bp) when digested with Bsa I. PCR products were directly analyzed on a $2.5 \%$ agarose gel. ${ }^{24}$

\section{Determination of GSTT1 and GSTM1 polymorphism}

The polymorphic deletion of the GSTT1 and GSTM1 genes were genotyped using the multiplex PCR approach. The primers used for GSTT1 and GSTM1 amplification were F5' -TTC CTT ACT GGT CCT CAC ATC TC-3', R5'-TCA CCG GAT CAT GGC CAG CA-3' and F5'GAA CTC CCT GAA AAG CTA AAG C-3'; R5'-GTT GGG CTC AAA TAT ACG GTG G-3', respectively. The B-globin gene primer pairs were F5' -CAA CTT CAT CCA CGT TCA CC-3', R5' - GAA GAG CCA AGG ACA GGT AC-3'. In the thermocycling procedure, initial denaturation at $94^{\circ} \mathrm{C}$ for 4 minutes was followed by 35 cycles of 1 minute at $94{ }^{\circ} \mathrm{C}, 45$ seconds at $55{ }^{\circ} \mathrm{C}, 1$ minute at $72{ }^{\circ} \mathrm{C}$ and final extension was 10 minutes at $72{ }^{\circ} \mathrm{C}$. Genotyping of the genes (null genotypes) is revealed by the absence of the $480 \mathrm{bp}$ for GSTT1 and $219 \mathrm{bp}$ for GSTM1 PCR products respectively, using the $B$-globin amplification (110 bp) as an internal positive control. PCR products for the genotyping of polymorphisms were visualized by $2 \%$ agarose gel electrophoresis with ethidium bromide. The absence of $\mathrm{B}$-globin amplification indicated a failure of PCR reaction. ${ }^{25}$

\section{Statistical analysis}

Differences between the two groups for categorical variables were analyzed by Chi Square (c2) test. The association between AML and CYP1A1, GST1 gene polymorphisms was evaluated by odds ratios and their confidence intervals. P-values less than 0.05 were considered significant. A low-risk genotype (presence of GST1 ( $M$ and T) and CYP1A1 genotype $C / C$ ) was used as the baseline (referent) for calculating OR.

\section{RESULTS}

This study was done on 50 de novo AML before treatment induction. There was a male predominance in AML patient groups, $68 \%$ vs $32 \%$.CD7 was positive in $36 \%$ and negative in $64 \%$ of the studied AML patients. The laboratory parameters of AML patients at the time of diagnosis were also shown (Table I).

There was a significant increase in percentages of CYP1A1*4 genotypes CA and AA vs CC among AML patients compared to control group. The carriers of CYP1A1*4, CA and AA genotypes had an increased risk of developing $A M L(O R=3.25,95 \% \mathrm{Cl}: 1.01-10.46$, $\mathrm{p}=0.05$ ) on comparing $A M L$ patients with controls and using normal CYP1 $11^{*} 4 \mathrm{CC}$ as referent. Also, there was a significant increase in percentages of CYP1A1*4, A allele in AML patients as compared to control group and using normal $\mathrm{C}$ allele as referent ( $\mathrm{OR}=2.87,95 \%$ $\mathrm{Cl}: 1.23-6.68, \mathrm{p}=0.01$ ); Table II, Figure 1 .

As regards GST, using normal genotype (present gene) as referent, carriers of the null genotype had an increased risk of developing AML. The homozygote null GSTT1 genotype was significantly higher in AML patients than that in controls (OR 3.79, 95\% Cl: 1.11 12.87, $p=0.03$ ). On the other hand the GSTM1 showed no statistical significant difference in AML patients compared to the control $(\mathrm{OR}=1.85,95 \% \mathrm{Cl} 0.57-5.92$, $\mathrm{p}=0.3$ ). So, the most significant factor associated with increased risk of AML was the GSTT1 null genotype (Table II, Figure 2).

When the ORs were calculated for the combined CYP1A1*4 and GST genotypes, a combination of CYP1A1*4 (CC) and GST (present) gave a baseline as shown in Table 3. The OR for GSTT1 null genotype was 3.79 (95\% Cl: 1.11 - 12.87). The OR for CYP1A1*4(AA) was $4.51(95 \% \mathrm{Cl}: 1.08-18.52)$. However, the presence of these genotypes in combination enhanced the risk of $A M L$ with OR=12.66 (95\% Cl: 1.19-128.6) (Table III). Therefore, the combination of the two high-risk genotype CYP1A1*4 AA and GSTT1 null genotype showed increased cancer risk when compared with no-risk genotypes. In contrary, there was no significant difference with the combination of the CYP1A1*4(AA) with the GSTM1 null genotype $O R=1.8(95 \% \mathrm{Cl}: 0.2-15.74)$; Table III.

Table IV shows that, there is a significant difference in the response to treatment between AML patients related to their clinical and laboratory differences. The non response to treatment (NR) was assessed by bone marrow at the 14th day after treatment induction. Patients older than 60 years, having higher blast percentage, with higher LDH level and those expressing CD7 positivity showed a significant non response to treatment $(p=0.01,0.02,0.05$ and 0.001 respectively). Also, the genetic study of CYP1A1*4 and GST gene polymorphisms as regard its effect on the response to treatment showed a significant non response to treatment in those patient carrying the CYP1A1*4 (A) allele (OR, 4.15, 95\% Cl: $1.11-15.30, \mathrm{P}=0.03$ ) and those carry- 
ing the GSTT1 null genotype (OR,4.09, 95\% Cl: 1.25-13$.36, \mathrm{P}=0.02)$ compared to the $\mathrm{CYP} 1 \mathrm{~A} 1 * 4(\mathrm{C})$ allele and GSTT present allele. On the other hand those having the GSTM1null genotype showed no significant difference compared the present genotype.

There was a positive correlation between the GSTT1 null genotype with other prognostic markers in AML patients (presence of CD7, the increased blast count in the bone marrow, the level of serum LDH as well as the non response to treatment), however there was no correlation between this genotype and increased age in the AML patients (Table V).

Positive correlation was also found between the CYP1A1*4(A) allele and the other prognostic markers in AML patients (presence of CD7, the increased blast count in the bone marrow as well as the non response to treatment), however there was no correlation between this (A)allele and the serum level of LDH in the AML patients (Table VI).

Table I. Clinical and laboratory parameters of AML patients

\begin{tabular}{|c|c|}
\hline & AML patients $(\mathrm{N}=50)$ Mean \pm SD \\
\hline Age & $49 \pm 6.2$ \\
\hline Male (n \%) & $34(68 \%)$ \\
\hline Female & $16(32 \%)$ \\
\hline $\mathrm{Hb}(\mathrm{g} / \mathrm{dl})$ & $9.6 \pm 3.2$ \\
\hline $\operatorname{WBCs}\left(\mathbf{x 1 0 ^ { 3 }}\right)$ & $35.6 \pm 6.1$ \\
\hline Platelet $\left(\times 10^{9}\right)$ & $70+3$ \\
\hline Peripheral blood blast & $25+7.6$ \\
\hline Bone marrow blast & $50+8.9$ \\
\hline LDH & $760+124$ \\
\hline CD7 positive (n \%) & $18(36 \%)$ \\
\hline Negative & $32(64 \%)$ \\
\hline
\end{tabular}

Table II. Genotyping of the GSTT and CYP1A1 in the studied AML patients and the control group

\begin{tabular}{|c|c|c|c|c|c|}
\hline & $\begin{array}{c}\text { GI } n=15 \\
\text { NK }\end{array}$ & $\begin{array}{c}\text { GII } n=50 \\
N \%\end{array}$ & OR & $95 \% \mathrm{Cl}$ & P \\
\hline \multicolumn{6}{|c|}{ CYP1A1"4 genotype } \\
\hline $\mathrm{CC}$ & $8(53.3)$ & $13(26)$ & & referent & \\
\hline$A C$ & $4(26.7)$ & $15(30)$ & 2.31 & $0.58-8.95$ & 0.24 (CAnsCC) \\
\hline$A A$ & $3(20)$ & $22(44)$ & 4.51 & $1.08-18.52$ & $0.04^{*}(\mathrm{AAvSCC})$ \\
\hline$A C+A A$ & $7(23.3)$ & $37(37)$ & 3.25 & $1.01-10.46$ & $0.05^{*}(\mathrm{CA}+\mathrm{A} A v \mathrm{~s} C \mathrm{C})$ \\
\hline C(allel) & $20(66.7)$ & $41(41)$ & 1 & referent & \\
\hline A (allel) & $10(33.3)$ & $59(59)$ & 2.87 & $1.23-6.68$ & $0.01^{*}($ AvsC) \\
\hline \multicolumn{6}{|c|}{ GSTI 1 genotype } \\
\hline present & $11(73.3)$ & $21(42)$ & & Referent & \\
\hline null & $4(26.7)$ & -29.58 & 3.79 & $1.11-12.87$ & $0.03^{*}($ null vst) \\
\hline \multicolumn{6}{|c|}{ GSTM1 genotype } \\
\hline present & $10(66.7)$ & $26(52)$ & & Referent & \\
\hline null & $5(33.3)$ & $24(48)$ & 1.85 & $0.57-5.92$ & 0.32 (null vst) \\
\hline
\end{tabular}

*Significance $\leq 0.05$

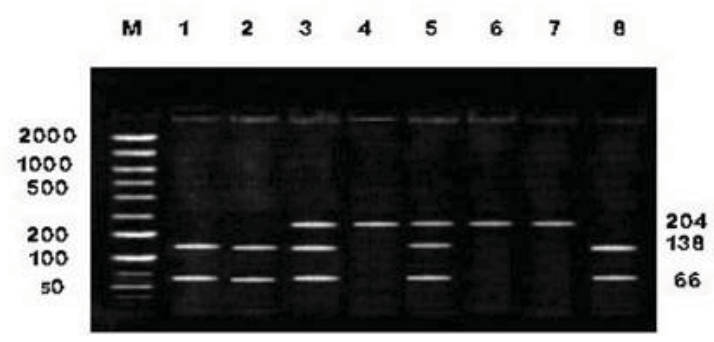

Figure 1. CYP1A1*4 gene polymorphism in $\mathrm{AML}$ patients and control group M: moecular marker (50 bp ladder)

Lane 1, 2, 8: represent the CC genotype

Lane 3, 5: represent heterozygous mutation (AC) genotype

Lane 4, 6, 7: represent homozygous mutation (AA) genotype

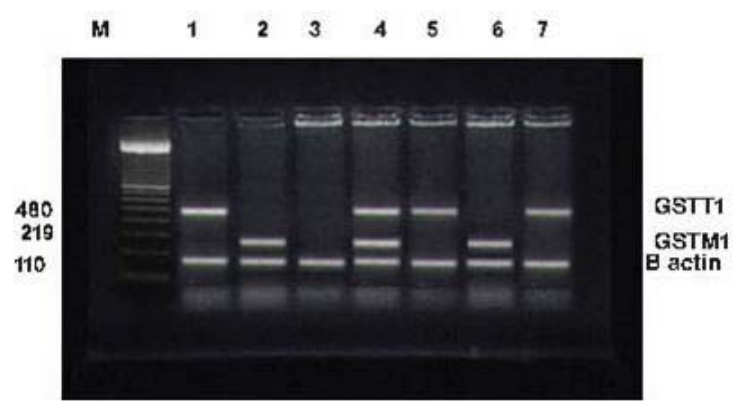

Figure 2. GSTT1 and GSTM1 gene polymorphism in the $\mathrm{AML}$ patients and control group

$M$ : the molecular marker

Lane 1, 5, 7: represent the GSTT1 null genotype Lane 2, 6: represent the GSTM1 null genotype Lane 3: represent the GSTT1 and GSTM1null genotype

Lane 4: represent the GSTT1and GSTM1present genotype

Table III. Relative risk of AML for combined CYP1A1 and GSTT1 genotype

\begin{tabular}{|c|c|c|c|c|c|}
\hline $\begin{array}{l}\text { Combined CYPI } \\
\text { GST genotypes }\end{array}$ & 1 and & $\begin{array}{l}\text { Group (I) } \\
(n=15)\end{array}$ & $\begin{array}{l}\text { Group (II) } \\
(n=50)\end{array}$ & OR (95\%Cl) & p \\
\hline CC and GSTI1 & $\begin{array}{l}+ \\
\text { Null }\end{array}$ & $\begin{array}{l}7(46.7) \\
1(6.7)\end{array}$ & $\begin{array}{l}11(22) \\
2(4)\end{array}$ & $\begin{array}{c}\text { referent } \\
1.27(1.13-11.35)\end{array}$ & 0.8 \\
\hline CA and GSTT1 & $\begin{array}{l}+ \\
\text { Null }\end{array}$ & $\begin{array}{l}2(13.3) \\
1(13.3)\end{array}$ & $\begin{array}{l}7(14) \\
8(16)\end{array}$ & $1.14(0.15-8.48)$ & 0.9 \\
\hline AA and GSTT1 & $\begin{array}{l}+ \\
\text { Null }\end{array}$ & $\begin{array}{l}2(13.3) \\
1(6.7) \\
\end{array}$ & $\begin{array}{l}3(6) \\
19(38) \\
\end{array}$ & $12.66(1.19-128.6)$ & $0.03^{*}$ \\
\hline CC and GSTM1 & $\begin{array}{l}+ \\
\text { Null }\end{array}$ & $\begin{array}{l}7(46.7) \\
1(6.7)\end{array}$ & $\begin{array}{l}10(20) \\
3(6)\end{array}$ & $\begin{array}{c}\text { referent } \\
2.1(0.23-17.26)\end{array}$ & 0.5 \\
\hline CAand GSTM1 & $\begin{array}{l}+ \\
\text { Null }\end{array}$ & $\begin{array}{l}2(13.3) \\
2(13.3)\end{array}$ & $\begin{array}{l}5(10) \\
9(18)\end{array}$ & $1.8(0.24-14.04)$ & 0.6 \\
\hline AA and GSTM1 & $\begin{array}{l}+ \\
\text { Null }\end{array}$ & $\begin{array}{l}1(6.7) \\
2(13.3)\end{array}$ & $\begin{array}{l}11(22) \\
12(24)\end{array}$ & $1.8(0.20-15.74)$ & 0.6 \\
\hline
\end{tabular}

*Significance $\leq 0.05$ 
Table IV. The response to treatment in the studied AML patient groups

\begin{tabular}{|c|c|c|c|c|c|}
\hline & $\begin{array}{l}\text { Total } \\
\text { N\% }\end{array}$ & $\begin{array}{l}\text { CR } \\
N \%\end{array}$ & $\begin{array}{l}\text { NR } \\
\text { N\% }\end{array}$ & OR (95\%Cl) & $\mathbf{p}$ \\
\hline $\begin{aligned} \text { Age } & \leq 55 \\
& >55\end{aligned}$ & $\begin{array}{l}18(36) \\
32(64)\end{array}$ & $\begin{array}{l}13(26) \\
11(22)\end{array}$ & $\begin{array}{l}5(10) \\
21(42)\end{array}$ & $4.96(1.44-16.97)$ & $0.01^{*}$ \\
\hline $\begin{aligned} \text { LDH } & \leq 400 \\
& >400\end{aligned}$ & $\begin{array}{l}24(48) \\
26(52) \\
\end{array}$ & $\begin{array}{l}14(28) \\
8(16)\end{array}$ & $\begin{array}{l}10(20) \\
18(36) \\
\end{array}$ & $3.15(1.01-9.91)$ & $0.05^{*}$ \\
\hline $\begin{aligned} \text { WBCs } & \leq 30 \\
& >30\end{aligned}$ & $\begin{array}{l}18(36) \\
32(64) \\
\end{array}$ & $\begin{array}{l}11(22) \\
21(42) \\
\end{array}$ & $\begin{array}{r}7(14) \\
11(22) \\
\end{array}$ & $1.22(0.38-3.93)$ & 0.75 \\
\hline $\begin{aligned} \text { Blast\% } & \leq 50 \\
& >50\end{aligned}$ & $\begin{array}{l}21(42) \\
29(58)\end{array}$ & $\begin{array}{l}15(30) \\
11(22)\end{array}$ & $\begin{array}{l}6() \\
18(1) \\
\end{array}$ & $4.09(1.25-13.36)$ & $0.02^{*}$ \\
\hline $\begin{array}{ll}\text { CD7 } & \text { positive } \\
& \text { negative }\end{array}$ & $\begin{array}{l}32(64) \\
18(36) \\
\end{array}$ & $\begin{array}{c}21(42) \\
3(6)\end{array}$ & $\begin{array}{l}11(22) \\
15(30) \\
\end{array}$ & $9.54(2.37-34.42)$ & $0.001^{*}$ \\
\hline $\begin{array}{l}\text { CYP1A1*4 } \\
C C \\
C A+A A \\
\end{array}$ & $\begin{array}{l}13(26) \\
37(74)\end{array}$ & $\begin{array}{l}9(18) \\
13(26)\end{array}$ & $\begin{array}{c}4(8) \\
24(48)\end{array}$ & $4.15(1.11-15.30)$ & $0.03^{*}$ \\
\hline $\begin{array}{l}\text { GST1 } \\
+ \\
\text { null } \\
\end{array}$ & $\begin{array}{l}21(42) \\
29(58)\end{array}$ & $\begin{array}{l}17(34) \\
11(22)\end{array}$ & $\begin{array}{c}4(8) \\
18(36)\end{array}$ & $4.09(1.25-13.36)$ & $0.02^{*}$ \\
\hline $\begin{array}{l}\text { GSTM1 } \\
+ \\
\text { null } \\
\end{array}$ & $\begin{array}{l}26(52) \\
24(48)\end{array}$ & $\begin{array}{l}15(30) \\
11(22)\end{array}$ & $\begin{array}{l}11(22) \\
13(26)\end{array}$ & $1.61(0.5-4.86)$ & 0.4 \\
\hline
\end{tabular}

*Significance $\leq 0.05$

Table V. The correlation between the GSTT1null genotype and prognostic markers in AML patient groups

\begin{tabular}{|l|c|c|}
\hline \multirow{2}{*}{} & \multicolumn{2}{|c|}{ GST1 null } \\
\cline { 2 - 3 } & $\mathrm{r}$ & $\mathrm{P}$ \\
\hline Non response & 0.532 & $0.04^{*}$ \\
\hline CD7+ & 0.362 & $0.05^{*}$ \\
\hline Blast in B.M & 0.425 & $0.03^{*}$ \\
\hline LDH & 0.756 & $0.01^{*}$ \\
\hline Age > 55 & 0.335 & 0.057 \\
\hline
\end{tabular}

*Significance $\leq 0.05$

Table VI. The correlation between the CYP1A1*4 (A) allele and prognostic markers in AML patient groups

\begin{tabular}{|c|c|c|}
\hline & \multicolumn{2}{|c|}{ CYP1A1*4 (A) allele } \\
\hline & $\mathbf{r}$ & $\mathbf{P}$ \\
\hline Non response & 0.752 & $0.036^{*}$ \\
\hline CD7 & 0.436 & $0.049^{*}$ \\
\hline Blast in B.M & 0.412 & $0.046^{*}$ \\
\hline LDH & 0.325 & 0.12 \\
\hline Age $>55$ & 0.542 & $0.036^{*}$ \\
\hline
\end{tabular}

*Significance $\leq 0.05$

\section{DISCUSSION}

DNA damage in the hematopoietic precursor cell is the essential prerequisite for the development of acute myeloid leukemia (AML). Such damage may result from the interaction of reactive species generated by environmental or endogenous metabolites. Humans vary in their ability to metabolize such reactive intermediates, which may explain differences in leukemia risk as a result of the interplay of genetic susceptibility and exogenous exposure. ${ }^{26}$

Although acute myeloid leukemia (AML) is one of the most common malignancies worldwide, the relation between environmental and genetic factors and $A M L$ has not been shown clearly. Therefore, the present study was planned to elucidate the influence of genetic polymorphisms of both CYP1A1 and GST genes in the predisposition to acute myeloid leukemia as well as study the influence of these polymorphism in the response to treatment in patients with AML. Acute myeloid leukemia (AML) occurs predominately in adults, and it afflicts the elderly more frequently than the young. ${ }^{27}$

This study was done on 50 patients with acute myeloid leukemia, they were 20 patients younger than 55 years (group II) and 30 patients older than 55 years (group III). Fifteen apparently healthy individuals were included as a control group (group I).

As regards to the clinical presentation, pallor was significantly manifested in older age group than the younger age AML group (group III and group II respectively). There was a male predominance in both groups. These results were in accordance with that reported by Pascual et al, they stated that acute leukemia (AL) is more common in males of all age groups. ${ }^{28}$ Because there is no current environmental hypothesis to explain the higher incidence of acute leukemia in males, it could be hypothesized that females are genetically better protected than males against environmental and toxic agents that cause AL. In this regard, a study carried out among Malaysians by Jackson et al, suggested the presence of a gene located near the $A B O$ locus on chromosome 9, which could protect women with a group 0 blood type against AL. ${ }^{29}$ Additionally, several results suggest a possible role of sex steroids in the control of the proliferation of leukemic cells. For example, it has been reported that the antiproliferative effect of 17- $B$ estradiol on the human monoblastic cell line $U 937$ is more powerful than that of testosterone. ${ }^{30}$

There is a metabolic balance between CYP1A1 (Phase I) and GST (Phase II) enzymes. Pro-carcinogens that enter the cell are transformed into active carcinogens by the CYP1A1 enzyme. Formed active carcinogens are detoxified by GST enzymes involved in the detoxification processes by conjugating with glutathione, glucuronide or sulphate. ${ }^{31}$ As the equilibrium between these two enzymes is critical in the host's response to xenobiotics, results suggested a possible accumulation 
of reactive intermediates in individuals with higher CYP1A1 activity and deletion of GST, increasing the risk of DNA damage. Increasing DNA adducts cause different kinds of mutations in tumor suppressor genes and oncogenes and thus cancer cell development may be triggered. Therefore, people with an altered ability to activate pro-carcinogens and detoxify carcinogens may have an increased risk of developing cancer and contributing to leukemogenesis. ${ }^{26}$

In the present study the percentages of both CYP1A1*4 CA, AA genotypes and A allele was significantly higher in AML patients compared to the control group (group I). The carriers of CYP1A1*4, CA and AA genotypes had an increased risk of developing $A M L$. This results came in accordance with the results of Maria et al, who reported increased percentage of CYP1A $1 * 4$ in AML patients. ${ }^{32}$ Also, Gallegos et al, reported that the increased frequency of CYP1A1 genotype among $A M L$ patients is a risk factor for developing AML. ${ }^{33}$ Furthermore, Francesco et al, reported that a higher prevalence of CYP1A1*4 (A) allele was found in AML patients and was associated with a 2.2-fold increased risk of acute myeloid leukemia. ${ }^{26}$

Glutathione S-transferases (GSTs) are a family of cytosolic enzymes contributing to the detoxification of activated carcinogens. ${ }^{1-3}$ Substrates for the GST enzymes are environmental pollutants, such as benzo(a) pyrene and other polyaromatic hydrocarbons, but also anticancer drugs, including alkylating agents, anthracyclines, and cyclophosphamide metabolites. ${ }^{25}$

As regards to GST, the present study showed that, the homozygote null GSTT1 genotype was significantly higher in $\mathrm{AML}$ patients than that in control group. Carriers of GSTT1 null genotype had an increased risk of developing AML. On the other hand the GSTM1 showed no statistical significant difference in AML patients compared to the control group. This came in agreement with that reported by Setiawan et al, who reported that GSTT1 present genotype may be a protective factor for AML and null genotype people were more at risk to be afflicted with AML. ${ }^{34}$

The results of the present study also showed that the combination of the two high-risk genotype CYPIA1 AA and GSTT1 null genotype showed increased AML risk when compared with no-risk genotypes(CYP1A1*4 CC genotype and GSTT1 present genotype). These results come in agreement with that reported by Francesco et al, whose study reported that the GSTT1 null genotype and the cytochrome P450 CYP1A1*4 allele were significantly higher in patients with $A M L$ than in controls. ${ }^{26}$ The GSTT1 deletion conferred a 1.7-fold increase in the risk of $A M L$ and the CYP1A1*4 allele a 2.2-fold increase. The risk was even greater when null genotype of GSTT1 was combined with CYP1A1*4.

Although several parameters are useful for risk stratification of patients with acute myeloid leukaemia $(\mathrm{AML})$, there are no firm criteria for predicting response to induction treatment of individual patients.
The clearance of blasts from peripheral blood (PBC) correlated closely with response, as assessed by bone marrow on day 14, and by morphologic analysis at haematopoietic recovery. Therefore, a major treatment outcome can be predicted very early in AML patients, thus providing an opportunity for tailoring treatment modalities from the outset. ${ }^{19}$

In the present study, there was a significant difference in the response to treatment between younger age $A M L$ patients and older age AML patients. A rapid reduction of blasts was seen in all patients who eventually achieved complete remission (CR); by contrast, a slower reduction was seen in non response patients. The (CR) was better in younger than older age patients. These results came in accordance with Smith et al, who reported that, AML in older patients is frequently characterized by resistance to treatment due to host and leukemia related factors: the presence of co-morbid disease, such as diabetes, vascular insufficiency and renal impairment frequently compromises the hosts tolerance to aggressive chemotherapy, while the metabolism of chemotherabiotic drugs may be delayed due to an age-related decline in excretory function, thus resulting in exposure to higher drug level and grater toxicity. ${ }^{35} \mathrm{Also}$, Chen et al, and Pinto et al, reported that the outcome of elderly $A M L$ is generally poor as older patients may be less intensively treated compared with younger patients. ${ }^{36,37}$ In agreement with these results, Grimwade et al, stated that AML in older patients is biologically different from that occurring in younger patients. ${ }^{29}$ For example, older patients with AML tend to have more unfavorable cytogenetics and a higher rate of multidrug resistance gene expression, which might contribute significantly to their poor clinical outcome.

The prognostic significance of selected markers of leukemic cells is well known. CD7 and CD56 expression at diagnosis has been associated with low remission rates and biological aggressiveness in a significant proportion of acute leukemias. The expression of CD7 in patients with acute myeloid leukemia is associated with poorer prognosis. ${ }^{16,38}$ The comparatively accurate pretherapeutic identification of high-risk AML patients may prove useful for the development of individualized therapy protocols in stratified clinical patients groups. ${ }^{39}$

To date there is no parameter predicting early outcome of treatment in AML patients before the evaluation of response to induction chemotherapy. Many attempts to find an index characterizing a subgroup of AML patients at high risk of remission induction failure have been reported. The rapidity of disappearance of blasts from the bone marrow after the start of induction treatment has been studied; in fact, some studies have evaluated the response to induction therapy by assessing the degree of residual leukemic infiltration in the bone marrow following 6 or 14 days of chemotherapy. ${ }^{20}$

In the present study, AML patients expressing positive 
CD7 had lower complete remission (CR) manifested by the still present high blast percentage $\geq 5 \%$ in $B M$ at the 14th day treatment induction. These results came in accordance with Murat et al, who stated that, the complete remission rate, the overall survival and disease free survival rate of $C D 7$ positive AML cases was significantly lower than those of CD7 negative. ${ }^{15}$ Also, Kebede et al, reported that day $14 \mathrm{BM}$ is highly sensitive in predicting CR. ${ }^{40}$ Hong Chang et al, predicted the poor disease free survival and post-remission survival in patients with acute myeloid leukemia expressing CD7 positivity. ${ }^{41}$

In agreement with these results, Giacomo et al, reported that the clearance of blasts from peripheral blood (PBC) correlated closely with treatment response, as assessed by bone marrow on day 14, and by morphologic analysis at haematopoietic recovery. ${ }^{19}$ Therefore, a major treatment outcome can be predicted very early in AML patients, thus providing an opportunity for tailoring treatment modalities from the outset.

In this study it was found that, there was a positive correlation between the GSTT1 null genotype and the presence of CD7 positivity, the increased blast percentage in the bone marrow, the level of serum LDH as well as the non response to treatment, however no correlation was found between this genotype and increased age in the AML patients. Also, positive correlation was found between the CYP1A1*4(CA and $\mathrm{AA})$ genotype and the presence of CD7 positivity, the increased blast percentage in the bone marrow as well as the non response to treatment, however no correlation was found with the serum LHD level in the AML patients. These results came in agreement with Löwenberg and Kern et al, who reported that different clinical and prognostic parameters have a major role in predicting prognosis in newly diagnosed AML patients. ${ }^{22,42}$ In particular, age and early blast clearance have been found to be significantly related to CR rate and survival, better results being achievable in young adult patients.

\section{CONCLUSION}

From this study it was concluded that frequencies of some polymorphisms in genes of xenobiotic enzymes, GSTT1 null and the cytochrome P450 CYP1A1*4 (CA and $A A$ ) genotype or $A$ allele were significantly higher in patients with AML than in control which conferred an increased risk of AML. This risk is augmented by the combination of these two polymorphisms. Also, in AML patients these polymorphisms had a prognostic significance in treatment outcome where their presence confer an independent bad prognostic markers for complete remission in contrast with GSTT1 present genotype and CYP1 $11^{*} 4(\mathrm{CC})$ genotype. So, these two polymorphisms could be used to detect high risk group for AML. On the other hand in AML patients the use of GST and CYP1A1 genotype might complement other prognostic factors e.g. expression of CD7 positivity, thereby providing a more accurate risk assessment, which may ultimately permit a more refined treatment approach. This is achieved by the prognostic significance of the BMA at the 14th day of treatment induction to identify patients with resistant disease who might benefit from alternative therapeutic strategies. Therefore, pretherapeutic nonsurvival prediction in the relatively therapy-resistant AML may favor the indication for therapy intensification or early stem cell transplantation. It may also result in the search for early therapeutic interference points in case of premalignant myelodysplastic syndromes.

\section{REFERENCES}

1. Löwenberg B, Downing JR, Burnet A. Acute myeloid leukemia. N Engl J Med 2003; 341:105161

2. Henderson ES. Acute leukemia: general considerations. In: Williams WJ, Beutler E, Erslev AJ, Lichtman MA, eds. Hematology, 4th ed. New York: McGraw-Hill, 1990:237

3. Bowen DT, Frew ME, Rollinson S, Roddam PL, Dring A, Smith MT. CYP1A1*2B (Val) allele is overrepresented in a subgroup of acute myeloid leukemia patients with poor-risk karyotype associated with NRAS mutation, but not associated with FLT3 internal tandem duplication. Blood 2003; 101:2770-4

4. Sinnett D, Krajinovic M, Labuda D. Genetic susceptibility to childhood acute lymphoblastic leukemia. Leuk Lymphoma 2000; 38:447-62

5. Krajinovic M, Ghadirian P, Richer C, Sinnett H, Gandini S, Perret C. Genetic susceptibility to breast cancer in French-Canadians: role of carcinogen-metabolizing enzymes and geneenviroment interactions. Int J Canc 2001; 92:220-5

6. Ingelman-Sundberg M. Genetic susceptibility to adverse effects of drugs and environmental toxicants. The role of the CYP family of enzymes. Mutat Res 2001; 482:11-9

7. Butkiewicz D, Grzybowska E, Hemminki K, Ovrebo $S$, Haugen A, Motykiewicz G. Modulation of DNA adducts levels in human mononuclear white blood cells and granulocytes by CYP1A1, CYP2D6 and GSTM1 genetic polymorphisms. Mutat Res 1998; 415:97-108

8. Kawajiri K, Nakachi K, Imai K, Yoshii A, Shinoda $\mathrm{N}$, Watanabe J. Identification of genetically high risk individuals to lung cancer by DNA polymorphisms of the cytochrome P4501A1 gene. FEBS Lett 1990; 263:131-3

9. Hayashi S, Watanabe J, Nakachi K, Kawajiri K. Genetic linkage of lung cancer associated Mspl polymorphisms with amino acid replacement in the heme binding region of the human cytochrome P4501A1 gene. J Biochem 1991; 110:40711

10. Cascorbi I, Brockmöller J, Roots I. AC4887A polymorphysm in exon 7 of human CYP1A1: population frequency, mutation linkages, and impact on lung cancer susceptibility. Canc Res 
1996; 56:2965-9

11. Aktas D, Hascicek M, Sozen S, Ozen H, Tuncbilek E. CYP1A1 and GSTM1 polymorphic genotypes in patients with prostate cancer in a Turkish population. Cancer Genet Cytogenet 2004; 154:81-5

12. Chan CE, Lam SY, Fu KH, Kwong YL. Polymorphisms of the GSTM1, GSTP1, MPO, XRCC1, and NQ01 genes in Chinese patients with nonsmall cell lung cancer: relationship with aberrant promoter methylation of the CDKN2A and RARB genes. Cancer Genet Cytogenet 2005; 162:10-20

13. Salinas AE, Wong MG. Glutathione Stransferases a review. Curr Med Chem 1999; 6:279-309

14. El-Siss AH, El-Swaayed AF. Aberrant Lymphoid Antigen Expression in Acute Myeloid Leukemia in Saudi Arabia. J Egypt Nat Cancer Inst 2006; 18:244-9

15. Söker M, Ayyildiz O, Devecioglu C, Haspolat K. CD7 Positive Acute Myeloblastic Leukemia Exhibiting Pleural and Pericardial Involvement as an Initial Manifestation. Int Pediatr 2001; 16:211-3

16. Cruse JM, Lewis RE, Pierce S, Lam J, Tadros Y. Aberrant expression of CD7, CD56, CD79a antigens in acute myeloid leukemia. Exp Mol Pathol 2005, 79: 39-41

17. Tiftik N, Bolaman Z, Batun S, et al. The importance of CD7 and CD56 antigens in acute leukemias. Int J Clin Pract 2004; 58:149-58

18. Del Poeta G, Stasi R, Venditti A, et al. Prognostic value of cell marker analysis in de novo acute myeloid leukemia. Leukemia 1994; 8:388

19. Gianfaldoni G, Mannelli F, Baccini M, Antonioli E, Leoni1 F, Bosi A. Clearance of leukaemic blasts from peripheral blood during standard induction treatment predicts the bone marrow response in acute myeloid leukaemia. $\mathrm{Br} \mathrm{J}$ Haematol 2006; 134,54-7

20. Liso V, Albano F, Pastore D, et al. Bone marrow aspirate on the 14th day of induction treatment as a prognostic tool in de novo adult acute myeloid leukemia. Haematologica 2000; 85: 1285-90

21. Haferlach T, Kern W, Schoch C, et al. A new prognostic score for patients with acute myeloid leukemia based on cytogenetics and early blast clearance in trials of the German AML Cooperative Group. Haematologica 2004; 89:408-18

22. Kern W, Haferlach T, Schoch C, et al. Early blast clearance by remission induction therapy is a major independent prognostic factor for both achievement of complete remission and a longterm outcome in acute myeloid leukemia: data from the German AML Cooperative Group (AMLCG) 1992 Trial. Blood 2003; 101:64-70

23. Bennett JM, Catovsky D, Daniel MT, et al. Proposed revised criteria for the classification of acute myeloid leukemia. A report of the

French-American-British Cooperative Group. Ann Intern Med 1985; 103:620-5

24. Cascorbi I, Brockmöller J, Roots I. A C4887A polymorphysm in exon 7 of human CYP1A1: population frequency, mutation linkages, and impact on lung cancer susceptibility. Canc Res 1996; 56:2965-9

25. Voso MT, D'Alò F, Putzulu R, et al. Negative prognostic value of glutathione $\mathrm{S}$-transferase (GSTM1 and GSTT1) deletions in adult acute myeloid leukemia. Blood 2002; 100:2703-7

26. Francesco A, Maria TV, Francesco G, Giuseppina $\mathrm{M}$, Alessandra S. Polymorphisms of CYP1A1 and glutathione S-transferase and susceptibility to adult acute myeloid leukemia. Haematologica 2004; 89:6

27. Rathnasabapathy R, Lancet JE. Management of acute myelogenous leukemia in the elderly. Cancer Control 2003; 10:469-77

28. Pascual B, Maria C, Eva B, Jose C, Maria JC. The potential effect of gender in combination with common genetic polymorphisms of drug-metabolising enzymes on the risk of development of acute leukemia. Hematologica 2007, 92:308-14

29. Jackson N, Menon BS, Zarina W, Zawawi N, Naing $\mathrm{NN}$. Why is acute leukemia more common in males? A possible sex-determined risk linked to the ABO blood group genes. Ann Hematol 1999; 78:233-6

30. Mossuz P, Cousin F, Castinel A, et al. Effects of two sex steroids ( 17 beta estradiol and testosterone) on proliferation and clonal growth of the human monoblastic leukemia cell line, U937. Leuk Res 1998; 22:1063-72

31. Oude Ophuis MB, van Lieshout EM, Roelofs HM, Peters WH, Manni JJ. Glutathione S-Transferase M1 and T1 and Cytochrome P4501A1 Polymorphisms in Relation to the Risk for Benign and Malignant Head and Neck Lesions. Cancer 1998; 82:936-43

32. Voso MT, D'Alò F, Gumier D, Guidi F, Hohaus S, Leone $G$. The CYP1A1*2a allele is an independent prognostic factor for acute myeloid leukemia. Haematologica 2005; 90:982-4

33. Gallegos-Arreola MP, Batista-GonzJles CM, Delgado-Lamas JL, et al. Cytochrome P4501A1 polymorphism is associated with susceptibility to acute lymphoblastic leukaemia in adult Mexican patients. Blood Cells Mol Dis 2004; 33:326-9

34. Setiawan VW, Zhang ZF, Yu GP, Li YL, Tsai CJ. GSTT1 and GSTM1 null genotypes and risk of gastric cancer: A case-control study in a Chinese population. Cancer Epidemiol Biomarkers Prev 200; 9:73-80

35. Smith GA, Damon LE, Rugo HS, Ries CA, Linker CA. High-dose cytarabine dose modification reduces the incidence of neurotoxicity in patients with renal insufficiency. J Clin Oncol 1997; 15:833-9

36. Chen C, Yang CF, Yang MH, Lee KD, Kwang JY, You WK. Pretreatment prognostic factors and treatment outcome in elderly patients with de novo acute myeloid leukemia. Ann Oncol 2005; 16:1366-73

37. Pinto A, Zagonel V, Ferrara F. Acute myeloid 
leukemia in the elderly: biology and therapeutic strategies. Crit Rev Oncol Hematol 2001; 39:27587

38. Drexler HG, Thiel E, Ludwig WD. Acute myeloid leukemia expressing lymphoid associated antigen; diagnostic incidence and prognostic significance. Leukemia 1993; 7:489-98

39. Valet G, Repp R, Link H, Ehninger A, Gramatzki $M$. Pretherapeutic identification of high-risk acute myeloid leukemia (AML) patients from immunophenotypic, cytogenetics, and clinical parameters. Cytometry B Clin Cytom 2003; 53:4-10

40. Hussein K, Jahagirdar B, Gupta P, Burns L, Larsen $K$, Weisdorf $D$. Day 14 bone marrow biopsy in predicting complete remission and survival in acute myeloid leukemia. Am J Hematol 2008; 83:446-50

41. Chang H, Yeung J, Brandwein J, Yi QL. CD7 expression predicts poor disease free survival and post-remission survival in patients with acute myeloid leukemia and normal karyotype. Leuk Res 2007; 31:157-62

42. Löwenberg B. Prognostic factors in acute myeloid leukemia. Best Pract Res Clin Haematol 2001; $14: 65-75$ 
